\title{
Vancomycin revisited - 60 years later
}

\section{Ethan Rubinstein* and Yoav Keynan}

Department of Internal Medicine, University of Manitoba, Winnipeg, MB, Canada

\section{Edited by:}

Jos W. M. Van Der Meer, Radboud University Nijmegen Medical Centre, Netherlands

\section{Reviewed by:}

Antoine Andremont, University Paris Diderot, France

Ronald Paul Rabinowitz, University of Maryland School of Medicine, USA

*Correspondence:

Ethan Rubinstein, Department of Internal Medicine, University of

Manitoba, Winnipeg, MB, Canada e-mail: rubinste@cc.umanitoba.ca

\begin{abstract}
Vancomycin is one of the older antibiotics that has been now in clinical use close to 60 years. Earlier on, vancomycin was associated with many side effects including vestibular and renal, most likely due to impurities contained in early vancomycin lots. Over the years, the impurities have been removed and the compound has now far less vestibular adverse effects, but still possesses renal toxicity if administered at higher doses rendering trough serum levels of $>15 \mathrm{mcg} / \mathrm{mL}$ or if administered for prolonged periods of time. Vancomycin is effective against most Gram-positive cocci and bacilli with the exception of rare organisms as well as enterococci that became vancomycin resistant, mostly Enterococcus faecium. The major use of vancomycin today is for infections caused by methicillin-resistant Staphylococcus aureus (MRSA), methicillin-resistant Staphylococcus epidermidis (MRSE) and amoxicillinresistant enterococci. In its oral form, vancomycin is used to treat diarrhea caused by Clsotridium difficile. With S. aureus, there are only a handful of vancomycin-resistant strains. Nevertheless, a "vancomycin creep" that is slow upward trending of vancomycin MIC from $<1 \mathrm{mcg} / \mathrm{mL}$ to higher values has been noted in several parts of the world, but not globally, and strains that have MIC's of $1.5-2 \mathrm{mcg} / \mathrm{mL}$ are associated with high therapeutic failure rates. This phenomenon has also been recently recognized in methicillin-susceptible $S$. aureus (MSSA). While vancomycin is relatively a safe agent adverse events include the "red man" syndrome, allergic reactions, and various bone marrow effects as well as nephrotoxicity. Vancomycin has been a very important tool in our therapeutic armamentarium that remained effective for many years, it is likely remain effective as long as resistance to vancomycin remains controlled.
\end{abstract}

Keywords: vancomycin, MRSA, VRE, "red man" syndrome, nephrotoxicity, oral-vancomycin, safety, dose
Vancomycin was isolated in 1957 by Dr. E.C Kornfield, an organic chemist with Eli Lilly in the deep jungles in Borneo from a fungus named Streptomyces orientalis. Soil samples from that jungle of where the fungus was isolated yielded in broth fermentation a compound that was highly effective and bactericidal against Staphylococci. The initial compound was labeled 05865 and initial studies have shown that Staphylococci failed to develop resistance to 05865 following serial passages in media containing this agent. As in this period, there was a growing problem of drug-resistant Staphylococci, the FDA granted 05865 a "fast track approval," on the basis of open - labeled studies submitted to the agency in 1958. 05865 was subsequently labeled as "vancomycin," a term derived from the word vanquish. The original productvancomycin, obtained by fermentation, contained considerable amounts (up to 70\%) of impurities, and had a brown color earning it the nickname "Mississippi Mud" $(1,2)$.

Vancomycin is active against Gram-positive aerobic cocci and bacilli, e.g., Staphylococci, Streptococci, Enterococci, and Pneumococci as well as Corynebacterium, Listeria, Bacillus spp, Clostridia, and oral Gram-positive anaerobes. Vancomycin is active against methicillin-resistant Staphylococcus aureus (MRSA) and against methicillin-resistant Staphylococcus epidermidis (MRSE), as well as against penicillin-resistant Corynebacterium jeikeium, Streptococcus pneumoniae, and Clostridium difficile. Strains of Leuconosoc,
Lactobacillus, Pediococcus, and Erysipelothrix possess inherent resistance to vancomycin.

Vancomycin remains the first-line agent for methicillinresistant coagulase-negative and coagulase-positive staphylococcal infections, including bacteremia, endocarditis, pneumonia, cellulitis, and osteomyelitis. In addition, it is used to treat serious Gram-positive infections among patients who are allergic to semi-synthetic penicillins or cephalosporins (3).

While vancomycin is bactericidal against all susceptible Grampositive pathogens it exerts only bacteriostatic activity against enterococci and needs to be combined with another agent, usually an aminoglycoside, to achieve bactericidal activity. In addition, vancomycin possesses activity against Gram-positive anaerobes including Clostridium species as well as oral anaerobes such as peptostreptococcus, propiobacterium, etc. (including C. difficile), but is lacking activity against Gram-negative bacilli. Vancomycin "slow bactericidal" activity against MSSA, compared to $\beta$-lactams, this slow activity is reflected also in the worse clinical outcomes of cases of MSSA bacteremia and pneumonia treated with vancomycin (4-7).

Vancomycin is a tricyclic glycopeptide (Figure 1) that consists of seven membered peptide chains forming the tricyclic structure and attached disaccharide composed of vancosamine and glucose. The molecular weight is 1485 and thus vancomycin is heavier 


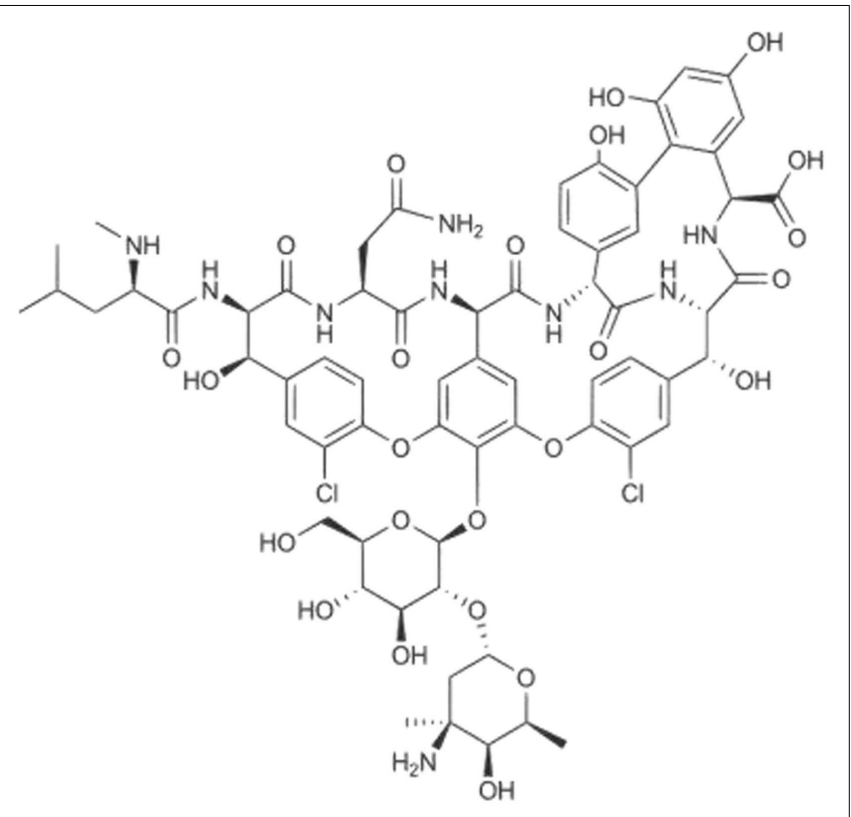

FIGURE 1 | Vancomycin structure

that most $\beta$-lactam antibiotics, but similar in weight to the unrelated compound daptomycin. It has similar molecular weight to teicoplanin and its derivative dalbavancin, to the semi-synthetic telavancin, as well as the more distantly related semi-synthetic lipoglycopeptide oritavancin (8).

Vancomycin and the above mentioned compounds inhibit cell wall synthesis in its later stages thus affecting dividing bacteria. The target of their activity is the murein monomers, which are peptidoglycan precursors. The murein monomers are added to the peptidoglycan by transglycosylation followed by transpeptidation. Vancomycin binds to the D-ala-D-ala moiety of the monomers, subsequently the monomers cross the cell membrane. This complex leads to conformational change that blocks the glycosyltransferase leading to inhibition of the incorporation of the murein monomers to the growing peptidoglycan chain and preventing further transpeptidation with consequent interruption of the cell wall synthesis.

When methicillin and subsequently other anti-staphylococcal penicillins (cloxacillin, dicloxacillin, flucloxacillin, etc.) were introduced to the market, the clinical utility of vancomycin was displaced from its position as first-line anti-staphylococcal therapy to second-line anti-staphylococcal therapy, mainly because of its nephrotoxicity and ototoxicity observed in the early clinical trials (1). It is clear today, that earlier observations of nephrotoxicity and ototoxicity were largely due to the impurities of the earlier preparations. The additional compounds accounted to up to $70 \%$ of vancomycin contained in the injection vials. Later, in the 1970 s when newer preparations of vancomycin were introduced, the issue of ototoxicity has essentially disappeared and nephrotoxicity was diminished considerably unless vancomycin was used in combination with aminoglycosides; the same was also seen in animal experiments $(9,10)$.
Vancomycin is in broad clinical use with the main indications including skin and soft tissue infections and osteomyelitis. It is used for these indications empirically, prior to availability of culture results, and when MRSA is the culprit. Similarly, it is frequently used for treatment of bacteremia and endocarditis where MRSA is deemed a possible cause. In this context, once MSSA is documented as the causative agent, vancomycin has been associated with inferior outcomes and should therefore not be used for MSSA bacteremia or endocarditis (4-7). In addition, vancomycin is used to treat gram-positive pneumonia, primarily in context of hospital-acquired infections and in the treatment of bacterial meningitis caused by penicillin-resistant Streptococcus pneumonia. The worldwide emergence of methicillin-resistant Staphylococci (MRSA and MRSE) in the 1970s, brought vancomycin back to the stage. At this juncture, pharmacokinetics became popular and blood concentrations were determined, and the first normograms with dosage adjustments for patients with renal impairment were published (11).

The subsequent emergence of vancomycin resistance among enterococci in the mid-1980s and failure of such patients even if they had enterococci with vancomycin-intermediate susceptibility was described, resulting in vancomycin losing it omnipotence for all gram-positive cocci (12). The appearance of S. aureus strains with intermediate susceptibility to vancomycin (VISA) and vancomycin-resistant $S$. aureus (VRSA) (12-14) and vancomycinresistant $S$. epidermidis (VRSE) $(15,16)$, brought an end to the hitherto hegemony of vancomycin in the Gram-positive coccal arena. Fortunately, the occurrence of these difficult to treat Staphylococci remains rare.

Normally, the suggested minimal inhibitory concentration (MIC) of vancomycin against $S$. aureus was $\leq 2 \mathrm{mcg} / \mathrm{mL}$. It has been repeatedly shown that clinical failures in patients with endocarditis, bacteremia, and pneumonia occur when the $S$. aureus strains causing these infections have MIC of $\geq 2 \mathrm{mcg} / \mathrm{mL}$ (17-19). Even within the range of MICs below $2 \mathrm{mcg} / \mathrm{mL}$, a high failure rate was also observed in patients infected with strains that has vancomycin MIC of $1.5(20,21)$.

A phenomenon named "vancomycin Creep" was described in recent years denoting a slow but steady increase in vancomycin MIC observed over time, from values of $0.5-0.75 \mathrm{mcg} / \mathrm{mL}$ to levels of $1.25-1.5 \mathrm{mcg} / \mathrm{mL}(22,23)$. In some parts of the world, however, this phenomenon of "vancomycin creep" does not occur (24).

Therapeutic monitoring of vancomycin levels in adults: for many years a disagreement existed regarding the need for measurement of vancomycin levels. The discussion was justified as long as most vancomycin MIC were $\leq 1 \mathrm{mcg} / \mathrm{mL}$, this situation has, however, changed and with increasing MIC's a decreased clinical success became evident $(25,26)$. In patients infected with strains that had MIC of $4 \mathrm{mcg} / \mathrm{mL}$ and above the failure rate of vancomycin reached $60 \%$, this has led many bodies (FDA, ICLS) to reduce in 2008 the limit of susceptibility (breakpoint) to $2 \mathrm{mcg} / \mathrm{mL}$. The other reason for measuring serum concentrations is to avoid toxicity, which becomes apparent when serum trough levels exceed $15 \mathrm{mcg} / \mathrm{mL}$ (27-29).

Vancomycin resistance among enterococci is attributed to change in the D-alanyl-D-alanine portion of peptide precursor units, transmitted as Van genes, thus rendering it incapable of 
inhibiting peptidoglycan polymerase and transpeptidation reactions. While the mechanisms that lead to vancomycin resistance are clear, the reasons behind the emergence of these strains are attributed to a myriad of causes (30-32). Thus far, at least eight types of acquired resistance to glycopeptides have been reported on the basis of phenotypic and genotypic criteria (VanA, VanB, VanD, VanE, VanG, VanL, VanM, VanN, and VanC). VanC being constitutively expressed by Enterococcus gallinarum and Enterococcus casseliflavus $(33,34)$. Carriage of VRE in the gastrointestinal tract occurs more commonly after prolonged hospital admissions and more frequently in high-risk units, such as intensive care units (ICUs), hemato-oncology, and abdominal surgery wards. VRE colonization may persist for years, and a recent study from Korea identified vancomycin exposure after colonization as the strongest predictor of prolonged colonization, with odds ratio of 4.05 in a multivariate model adjusting for potential confounders (35). It has been speculated that exposure to oral vancomycin is an important contributor to propagation of VRE in the healthcare setting, as it drives prolonged colonization with VRE from a myriad of sources $(36,37)$.

The challenge posed by MRSA with increasing vancomycin MIC's has led to attempts to treat such patients with higher doses of vancomycin aiming to attain a trough level of $>15 \mathrm{mcg} / \mathrm{mL}$, generally these attempts have not been associated with increased success rate, but rather with increased nephrotoxicity $(38,39)$. These doses are used in the context of $S$. aureus infections.

The effect of vancomycin antibacterial activity is pharmacokinetically dependent on the time that the serum concentration of vancomycin is above the MIC. In vitro and the neutropenic mouse thigh infection models have demonstrated that the area under the concentration curve (AUC) divided by the MIC (AUC/MIC) is the best predictor of the activity of vancomycin against methicillinsusceptible $S$. aureus (MRSA), and glycopeptide-intermediate $S$. aureus (GISA) (40). However, in a Streptococcus pneumoniae nonneutropenic mouse peritonitis model, Knudsen et al. (41) demonstrated that the peak serum concentration divided by the MIC (peak/MIC) was the pharmacodynamic parameter with the most predictive value. In patients with MRSA pneumonia an AUC/MIC value of $\geq 400$ was associated with a successful outcome, whereas an AUC/MIC value of $\leq 400$ was associated with a lower eradication rate and a higher mortality rate $(P=0.005)(42)$ With strains that have a MIC of $\geq 2 \mathrm{mcg} / \mathrm{mL}$ this desired AUC/MIC ratio of 400 is more difficult to achieve and attainment of lower AUC/MIC ratios has been associated with poorer outcomes in the context of bacteremia $(43,44)$.

Vancomycin is not appreciably absorbed orally, and is eliminated primarily via the renal route, with $>80-90 \%$ recovered unchanged in the urine within $24 \mathrm{~h}$ after administration of a single dose. The pharmacokinetic profile of vancomycin can be characterized by either a 2- or 3-compartment pharmacokinetic profile (45).

Vancomycin is normally administered intravenously, with a standard infusion time of at least $1 \mathrm{~h}^{\prime}$, to minimize infusion-related adverse effects. In patients with normal creatinine clearances, vancomycin has a $\alpha$-distribution phase of $\sim 30 \mathrm{~min}$ to $1 \mathrm{~h}^{\prime}$ and a $\beta$-elimination half-life of $6-12 \mathrm{~h}$. The volume of distribution is $0.4-1 \mathrm{~L} / \mathrm{kg}$. The binding of vancomycin to protein ranges from
10 to $50 \%$. Factors that affect the overall activity of vancomycin include its tissue distribution, inoculum size, and protein-binding effects (45-48).

Oral vancomycin is not absorbed systemically and achieves high levels in the colon thus oral vancomycin formulation may be used at a dose of $125 \mathrm{mg}$ q6h, and less frequently a higher dose of $500 \mathrm{mg}$ four times daily is equally effective (against $C$. difficile colitis). Oral vancomycin is indicated for patients with either severe $C$. difficile colitis (high leukocyte count $>15,000$, serum creatinine increase $\geq 50 \%$ from baseline), or those with $C$. difficile colitis that failed other therapeutic modalities (mainly metronidazole) (49). Intravenous vancomycin on the other hand, has no effect on $C$. difficile colitis since it is not excreted appreciably into the gastrointestinal tract. Intracolonic vancomycin administration at the same dose and frequency may be considered in patients with profound ileus. In patients with ileostomy, the same dose is administered as well.

Vancomycin-associated nephrotoxicity can still be seen, even in the presence of appropriate serum concentrations, especially when it is co-administered with aminoglycosides, amphotericin B, foscarnet, pentamidine ACE inhibitors, loop diuretics, cyclosporine, cyclophosphamide, and the platinums but also when vancomycin therapy exceeds 14 days and in patients with very high APACHE scores (50).

The most common adverse events that are not related to vancomycin serum levels are: fever, chills, and phlebitis. The "red man" (Figure 2) syndrome (RMS) is manifested by: tingling and red flushing of the face, upper torso, and upper extremities. It is thought to be mediated by histamine release from mast cells, it is considered as pseudo-allergic drug reaction without underlying immunological processes (51). The phenomena is enhanced by coadministration of opiates (52) and can be diminished or aborted by slowing the infusion rate of vancomycin to $\leq 10 \mathrm{mg} / \mathrm{min}$, and premedication with diphenhydramine $(50 \mathrm{mg}$ orally or intravenously) as well as ranitidine (50 mg orally or intravenously) (53). Should higher doses of vancomycin be administered $\left(>1 \mathrm{~g}^{\prime}\right)$ the infusion time needs to be prolonged if the RMS occurs.

Neutropenia is observed not infrequently in patients receiving vancomycin for longer periods of time. The exact incidence is difficult to ascertain due to co-administration of other potentially marrow suppressive medications and due to the underlying sepsis or diseases. This adverse event is not related to vancomycin serum concentrations, and is reversible when the agent is discontinued (54).

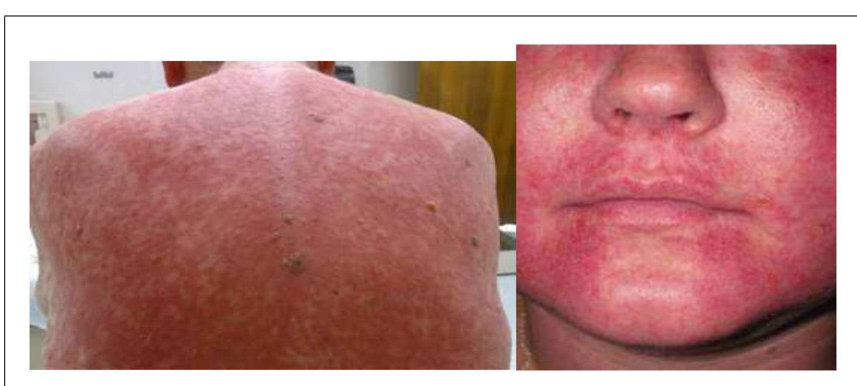

FIGURE 2 | “Red man” syndrome. 
Thrombocytopenia (immune), as well as leukocytosis, eosinophilia, and leukocytoclastic vasculitis have been associated with vancomycin $(55,56)$. Drug fever is considered infrequent and occasionally appears along with neutropenia (57).

Anaphylactic reaction is mediated by drug-specific IgE antibodies. Patients with anaphylactic reactions to vancomycin often have a history of multiple prior exposures, the reaction is considered rare, although angioedema, respiratory distress, and bronchospasm, with demonstrable drug-specific IgE have been described (58).

A cross allergic reaction between vancomycin and other glycopeptides has been described for teicoplanin but not for other glycopeptides (59).

Other dermatological manifestation of vancomycin are: DRESS (drug rash with eosinophilia and systemic symptoms) also named DiHS (drug-induced hypersensitivity syndrome). This is a systemic response, in which rash, mucosal involvement, atypical lymphocytes, frequent eosinophilia, and lymphadenopathy occur together with organ involvement (kidneys, liver, myocarditis/pericarditis). Treatment includes discontinuation of drug therapy and avoiding its use in the future and glucocorticoids for a short duration (60-62).

Vancomycin-related linear IgA bullous dermatosis (LABD) is a rare, autoantibody-mediated skin reaction. LABD may be confused with toxic epidermal necrolysis. The blistering bullous lesions of LABD need to be differentiated from pemphigoid, erythema multiforme, and dermatitis herpetiformis. Direct immunofluorescence is usually needed to confirm the diagnosis of LABD. Linear IgA deposition at the dermal-epidermal junction of the basement membrane zone is the characteristic finding of LABD. LABD can appear suddenly, appears to be idiosyncratic and unrelated to serum vancomycin levels $(63,64)$. Vancomycin is the most common cause of drug-induced LABD (65).

Other severe cutaneous syndromes including Stevens-Johnson syndrome, exfoliative dermatitis, toxic epidermal necrolysis, extensive fixed drug eruption, and leukocytoclastic vasculitis have all been described in association with vancomycin use $(66,67)$.

Desensitization procedure may be indicated for suspected IgEmediated reactions and for severe RMS that is refractory to other measures and is less common with availability of appropriate alternatives (such as linezolid, daptomycin, telavancin, quinupristin/dalfoprisin, tigecycline, and ceftaroline-all active against MRSA). Desensitization is contraindicated in patients with the DRESS syndrome and in those with exfoliative skin reactions such as Stevens-Johnson syndrome and toxic epidermal necrolysis. Desensitization for IgE-mediated allergy is usually performed in an intensive care unit. Desensitization should be performed immediately before the required treatment, because maintaining tolerance requires continual exposure to the drug. A rapid desensitization protocol (after up to date) is shown in Table 1.

Mild symptoms may occur in $20-30 \%$ during desensitization and are usually self-limited (e.g., flushing, pruritus, limited urticaria), and can be managed without discontinuation of the desensitization protocol (68). Mild symptoms are managed interruption of infusion and treating the symptoms that do not subside
Table 1 | Rapid vancomycin desensitization protocole (after up to date).

\section{Premedication:}

Diphenhydramine $50 \mathrm{mg} \mathrm{IV}$ and hydrocortisone $100 \mathrm{mg}$ IV $15 \mathrm{~min}$ prior to initiation of protocol, then every $6 \mathrm{~h}$ throughout protocol

\begin{tabular}{llll}
\hline Infusion no. & Dilution & $\begin{array}{l}\text { Vancomycin } \\
\text { dose }(\mathbf{m g})\end{array}$ & $\begin{array}{l}\text { Concentration } \\
\mathbf{( m g} / \mathbf{m L})\end{array}$ \\
\hline 1 & $1: 10,000$ & 0.02 & 0.0002 \\
2 & $1: 1000$ & 0.2 & 0.002 \\
3 & $1: 100$ & 2 & 0.02 \\
4 & $1: 10$ & 20 & 0.2 \\
5 & Standard & 500 & 2
\end{tabular}

\section{Preparation}

1. Prepare a standard bag of $500 \mathrm{mg}$ vancomycin in $250 \mathrm{~mL}$ NS or D5W; label as infusion number 5 , vancomycin $2 \mathrm{mg} / \mathrm{mL}$.

2. Draw up $10 \mathrm{~mL}$ of the standard vancomycin $2 \mathrm{mg} / \mathrm{mL}$ preparation and place in $100 \mathrm{~mL}$ bag of NS or D5W; label as infusion number 4 , vancomycin $0.2 \mathrm{mg} / \mathrm{mL}$

3. Draw up $10 \mathrm{~mL}$ of the $0.2-\mathrm{mg} / \mathrm{mL}$ solution and place in a $100-\mathrm{mL}$ bag of NS or D5W; label as infusion number 3 , vancomycin $0.02 \mathrm{mg} / \mathrm{mL}$.

4. Draw up $10 \mathrm{~mL}$ of the $0.02-\mathrm{mg} / \mathrm{mL}$ solution and place in a $100-\mathrm{mL}$ bag of NS or D5W; label as infusion number 2, vancomycin $0.002 \mathrm{mg} / \mathrm{mL}$.

5. Draw up $10 \mathrm{~mL}$ of the $0.002-\mathrm{mg} / \mathrm{mL}$ solution and place in a $100-\mathrm{mL}$ bag of NS or D5W; label as infusion number 1 , vancomycin $0.0002 \mathrm{mg} / \mathrm{mL}$.

\section{Infusion rate directions}

Initiate infusion rate at $0.5 \mathrm{~mL} / \mathrm{min}(30 \mathrm{~mL} / \mathrm{h})$ and increase by $0.5 \mathrm{~mL} / \mathrm{min}$ $(30 \mathrm{~mL} / \mathrm{h})$ as tolerated every $5 \mathrm{~min}$ to a maximum rate of $5 \mathrm{~mL} / \mathrm{min}$ $(300 \mathrm{~mL} / \mathrm{h})$. If pruritus, hypotension, rash, or difficulty breathing occurs, stop infusion and reinfuse the previously tolerated infusion at the highest tolerated rate. This step may be repeated up to three times for any given concentration.

Upon completion of infusion number 5, immediately administer the required dose of vancomycin in the usual dilution of NS or D5W over $2 \mathrm{~h}$. Decrease rate if patient becomes symptomatic or, alternatively, increase rate if patient tolerated dose. Administer diphenhydramine $50 \mathrm{mg}$ orally $60 \mathrm{~min}$ prior to each dose.

spontaneously. Once symptoms have subsided, the last tolerated step is repeated. If moderate or severe symptoms develop, the infusion should be discontinued and the symptoms treated. If vancomycin is discontinued, even for a short while, desensitization needs to be repeated in the previously described manner as the chances for anaphylaxis following the re-start of the vancomycin therapy are considerable (69).

Vancomycin has been a valuable agent for the management of infections caused by gram-positive bacteria for many decades. Attempts produce related derivatives as well as related compounds with similar or better antimicrobial spectrum, particularly against vancomycin-resistant enterococci and strains of VISA and MRSA with increased vancomycin MIC's are ongoing with notable examples including telavancin, dalbavancin, and oritavancin, the latter 
two poses longer half-lives and can be administered once-weekly. In addition distinct classes with similar spectrum of activity such as daptomycin and the streptogramin quinupristin/dalfopristin may be used.

In clinical trials, these compounds were compared to vancomycin and have been shown to be non-inferior $(38,70-76)$. This leads us to believe that vancomycin will continue to be used as the major glycopeptide antibiotic against MRSA and enterococci that are vancomycin susceptible, as long as agents with superior performance are not available.

\section{REFERENCES}

1. Griffith RS. Introduction to vancomycin. Rev Infect Dis (1981) 3(Suppl):S200-4. doi:10.1093/clinids/3.Supplement.S200

2. Moellering RC Jr. Vancomycin: a 50-year reassessment. Clin Infect Dis (2006) 42(Suppl 1):S3-4. doi:10.1086/491708

3. Liu C, Bayer A, Cosgrove SE, Daum RS, Fridkin SK, Gorwitz RJ, et al. Clinical practice guidelines by the infectious diseases society of America for the treatment of methicillin-resistant Staphylococcus aureus infections in adults and children. Clin Infect Dis (2011) 52(3):e18-55. doi:10.1093/cid/ciq146

4. Holmes NE, Turnidge JD, Munckhof WJ, Robinson JO, Korman TM, O'Sullivan $\mathrm{MV}$, et al. Vancomycin minimum inhibitory concentration, host comorbidities and mortality in Staphylococcus aureus bacteraemia. Clin Microbiol Infect (2013) 19(12):1163-8. doi:10.1111/1469-0691.12168

5. Kim SH, Kim KH, Kim HB, Kim NJ, Kim EC, Oh MD, et al. Outcome of vancomycin treatment in patients with methicillin-susceptible Staphylococcus aureus bacteremia. Antimicrob Agents Chemother (2008) 52(1):192-7. doi:10.1128/AAC.00700-07

6. Stryjewski ME, Szczech LA, Benjamin DK Jr, Inrig JK, Kanafani ZA, Engemann $\mathrm{JJ}$, et al. Use of vancomycin or first-generation cephalosporins for the treatment of hemodialysis-dependent patients with methicillin-susceptible Staphylococcus aureus bacteremia. Clin Infect Dis (2007) 44(2):190-6. doi:10.1086/510386

7. Khatib R, Johnson LB, Fakih MG, Riederer K, Khosrovaneh A, Shamse Tabriz M, et al. Persistence in Staphylococcus aureus bacteremia: incidence, characteristics of patients and outcome. Scand J Infect Dis (2006) 38(1):7-14. doi:10.1080/ 00365540500372846

8. Zhanel GG, Schweizer F, Karlowsky JA. Oritavancin: mechanism of action. Clin Infect Dis (2012) 54(Suppl 3):S214-9. doi:10.1093/cid/cir920

9. Brummett RE. Effects of antibiotic-diuretic interactions in the guinea pig model of ototoxicity. Rev Infect Dis (1981) 3(Suppl):S216-23. doi:10.1093/clinids/3. Supplement_2.S216

10. Farber BF, Moellering RC Jr. Retrospective study of the toxicity of preparations of vancomycin from 1974 to 1981. Antimicrob Agents Chemother (1983) 23(1):138-41. doi:10.1128/AAC.23.1.138

11. Moellering RC Jr, Krogstad DJ, Greenblatt DJ. Vancomycin therapy in patients with impaired renal function: a nomogram for dosage. Ann Intern Med (1981) 94(3):343-6. doi:10.7326/0003-4819-94-3-343

12. Fridkin SK, Hageman J, McDougal LK, Mohammed J, Jarvis WR, Perl TM, et al. Epidemiological and microbiological characterization of infections caused by Staphylococcus aureus with reduced susceptibility to vancomycin, United States, 1997-2001. Clin Infect Dis (2003) 36(4):429-39. doi:10.1086/346207

13. Hiramatsu K. Vancomycin-resistant Staphylococcus aureus: a new model of antibiotic resistance. Lancet Infect Dis (2001) 1(3):147-55. doi:10.1016/S14733099(01)00091-3

14. Howden BP, Davies JK, Johnson PD, Stinear TP, Grayson ML. Reduced vancomycin susceptibility in Staphylococcus aureus, including vancomycinintermediate and heterogeneous vancomycin-intermediate strains: resistance mechanisms, laboratory detection, and clinical implications. Clin Microbiol Rev (2010) 23(1):99-139. doi:10.1128/CMR.00042-09

15. Biavasco F, Vignaroli C, Varaldo PE. Glycopeptide resistance in coagulasenegative Staphylococci. Eur J Clin Microbiol Infect Dis (2000) 19(6):403-17. doi:10.1007/s100960000299

16. Strahilevitz J, Rubinstein E. Novel agents for resistant gram-positive infections a review. Int J Infect Dis (2002) 6(Suppl 1):S38-46. doi:10.1016/S1201-9712(02) 90153-0
17. Sakoulas G, Moise-Broder PA, Schentag J, Forrest A, Moellering RC Jr, Eliopoulos GM. Relationship of MIC and bactericidal activity to efficacy of vancomycin for treatment of methicillin-resistant Staphylococcus aureus bacteremia. J Clin Microbiol (2004) 42(6):2398-402. doi:10.1128/JCM.42.6.2398-2402.2004

18. Lodise TP, Graves J, Evans A, Graffunder E, Helmecke M, Lomaestro BM, et al. Relationship between vancomycin MIC and failure among patients with methicillin-resistant Staphylococcus aureus bacteremia treated with vancomycin. Antimicrob Agents Chemother (2008) 52(9):3315-20. doi:10.1128/ AAC.00113-08

19. Gómez J, García-Vázquez E, Baños R, Canteras M, Ruiz J, Baños V, et al. Predictors of mortality in patients with methicillin-resistant Staphylococcus aureus (MRSA) bacteraemia: the role of empiric antibiotic therapy. Eur J Clin Microbiol Infect Dis (2007) 26(4):239-45. doi:10.1007/s10096-007-0272-x

20. Gasch O, Camoez M, Dominguez MA, Padilla B, Pintado V, Almirante B, et al. Predictive factors for mortality in patients with methicillin-resistant Staphylococcus aureus bloodstream infection: impact on outcome of host, microorganism and therapy. Clin Microbiol Infect (2013) 19(11):1049-57. doi:10.1111/14690691.12108

21. van Hal SJ, Lodise TP, Paterson DL. The clinical significance of vancomycin minimum inhibitory concentration in Staphylococcus aureus infections: a systematic review and meta-analysis. Clin Infect Dis (2012) 54(6):755-71. doi:10.1093/cid/ cir935

22. Zhuo C, Xu YC, Xiao SN, Zhang GY, Zhong NS. Glycopeptide minimum inhibitory concentration creep among methicillin-resistant Staphylococcus aureus from 2006-2011 in China. Int J Antimicrob Agents (2013) 41(6):578-81. doi:10.1016/j.ijantimicag.2013.02.014

23. Sader HS, Fey PD, Limaye AP, Madinger N, Pankey G, Rahal J, et al. Evaluation of vancomycin and daptomycin potency trends (MIC creep) against methicillin-resistant Staphylococcus aureus isolates collected in nine U.S. medical centers from 2002 to 2006. Antimicrob Agents Chemother (2009) 53(10):4127-32. doi:10.1128/AAC.00616-09

24. Reynolds R, Hope R, Warner M, MacGowan AP, Livermore DM, Ellington MJ, et al. Lack of upward creep of glycopeptide MICs for methicillin-resistant Staphylococcus aureus (MRSA) isolated in the UK and Ireland 2001-07. JAntimicrob Chemother (2012) 67(12):2912-8. doi:10.1093/jac/dks324

25. Gould IM. Treatment of bacteraemia: methicillin-resistant Staphylococcus aureus (MRSA) to vancomycin-resistant S. aureus (VRSA). Int J Antimicrob Agents (2013) 42(Suppl):S17-21. doi:10.1016/j.ijantimicag.2013.04.006

26. Machado DP, Goldani LZ, Paiva RM, Aquino VR, de-Paris F, Lisboa T, et al. The impact of serum vancomycin levels and minimum inhibitory concentrations of methicillin-resistant Staphylococcus aureus on mortality in patients with nosocomial pneumonia. Can J Infect Dis Med Microbiol (2013) 24(3): e75-9.

27. Vandecasteele SJ, De Vriese AS, Tacconelli E. The pharmacokinetics and pharmacodynamics of vancomycin in clinical practice: evidence and uncertainties. J Antimicrob Chemother (2013) 68(4):743-8. doi:10.1093/jac/dks495

28. Roberts JA, Lipman J. Antibacterial dosing in intensive care: pharmacokinetics, degree of disease and pharmacodynamics of sepsis. Clin Pharmacokinet (2006) 45(8):755-73. doi:10.2165/00003088-200645080-00001

29. Lodise TP, Lomaestro B, Graves J, Drusano GL. Larger vancomycin doses (at least four grams per day) are associated with an increased incidence of nephrotoxicity. Antimicrob Agents Chemother (2008) 52(4):1330-6. doi:10.1128/ AAC.01602-07

30. Bonten MJ, Slaughter S, Ambergen AW, Hayden MK, van Voorhis J, Nathan C, et al. The role of "colonization pressure" in the spread of vancomycin-resistant enterococci: an important infection control variable. Arch Intern Med (1998) 158(10):1127-32. doi:10.1001/archinte.158.10.1127

31. Bonten MJ, Willems R, Weinstein RA. Vancomycin-resistant enterococci: why are they here, and where do they come from? Lancet Infect Dis (2001) 1(5):314-25. doi:10.1016/S1473-3099(01)00145-1

32. Murray BE. Vancomycin-resistant enterococcal infections. N Engl J Med (2000) 342(10):710-21. doi:10.1056/NEJM200003093421007

33. Courvalin P. Vancomycin resistance in gram-positive cocci. Clin Infect Dis (2006) 42(Suppl 1):S25-34. doi:10.1086/491711

34. Boyd DA, Willey BM, Fawcett D, Gillani N, Mulvey MR. Molecular characterization of Enterococcus faecalis N06-0364 with low-level vancomycin resistance harboring a novel D-Ala-D-Ser gene cluster, vanL. Antimicrob Agents Chemother (2008) 52(7):2667-72. doi:10.1128/AAC.01516-07 
35. Yoon YK, Lee SE, Lee J, Kim HJ, Kim JY, Park DW, et al. Risk factors for prolonged carriage of vancomycin-resistant Enterococcus faecium among patients in intensive care units: a case-control study. J Antimicrob Chemother (2011) 66(8):1831-8. doi:10.1093/jac/dkr204

36. Polgreen PM, Yang M, Kuntz JL, Laxminarayan R, Cavanaugh JE. Using oral vancomycin prescriptions as a proxy measure for Clostridium difficile infections: a spatial and time series analysis. Infect Control Hosp Epidemiol (2011) 32(7):723-6. doi:10.1086/660858

37. Currie BP, Lemos-Filho L. Evidence for biliary excretion of vancomycin into stool during intravenous therapy: potential implications for rectal colonization with vancomycin-resistant enterococci. Antimicrob Agents Chemother (2004) 48(11):4427-9. doi:10.1128/AAC.48.11.4427-4429.2004

38. Rubinstein E, Lalani T, Corey GR, Kanafani ZA, Nannini EC, Rocha MG, et al. Telavancin versus vancomycin for hospital-acquired pneumonia due to gram-positive pathogens. Clin Infect Dis (2011) 52(1):31-40. doi:10.1093/cid/ ciq031

39. Hidayat LK, Hsu DI, Quist R, Shriner KA, Wong-Beringer A. High-dose vancomycin therapy for methicillin-resistant Staphylococcus aureus infections: efficacy and toxicity. Arch Intern Med (2006) 166(19):2138-44. doi:10.1001/ archinte.166.19.2138

40. Rybak MJ. The pharmacokinetic and pharmacodynamic properties of vancomycin. Clin Infect Dis (2006) 42(Suppl 1):S35-9. doi:10.1086/491712

41. Knudsen JD, Fuursted K, Espersen F, Frimodt-Møller N. Activities of vancomycin and teicoplanin against penicillin-resistant pneumococci in vitro and in vivo and correlation to pharmacokinetic parameters in the mouse peritonitis model. Antimicrob Agents Chemother (1997) 41(9):1910-5.

42. Moise-Broder PA, Forrest A, Birmingham MC, Schentag JJ. Pharmacodynamics of vancomycin and other antimicrobials in patients with Staphylococcus aureus lower respiratory tract infections. Clin Pharmacokinet (2004) 43(13):925-42. doi:10.2165/00003088-200443130-00005

43. Kullar R, Leonard SN, Davis SL, Delgado G Jr, Pogue JM, Wahby KA, et al. Validation of the effectiveness of a vancomycin nomogram in achieving target trough concentrations of $15-20 \mathrm{mg} / \mathrm{L}$ suggested by the vancomycin consensus guidelines. Pharmacotherapy (2011) 31(5):441-8. doi:10.1592/phco.31. 5.441

44. Holmes NE, Turnidge JD, Munckhof WJ, Robinson JO, Korman TM, O'Sullivan $\mathrm{MV}$, et al. Vancomycin AUC/MIC ratio and 30-day mortality in patients with Staphylococcus aureus bacteremia. Antimicrob Agents Chemother (2013) 57(4):1654-63. doi:10.1128/AAC.01485-12

45. Matzke GR, Zhanel GG, Guay DR. Clinical pharmacokinetics of vancomycin. Clin Pharmacokinet (1986) 11(4):257-82. doi:10.2165/00003088-19861104000001

46. Matzke GR, McGory RW, Halstenson CE, Keane WF. Pharmacokinetics of vancomycin in patients with various degrees of renal function. Antimicrob Agents Chemother (1984) 25(4):433-7. doi:10.1128/AAC.25.4.433

47. Rodvold KA, Blum RA, Fischer JH, Zokufa HZ, Rotschafer JC, Crossley KB, et al. Vancomycin pharmacokinetics in patients with various degrees of renal function. Antimicrob Agents Chemother (1988) 32(6):848-52. doi:10.1128/AAC.32. 6.848

48. Golper TA, Noonan HM, Elzinga L, Gilbert D, Brummett R, Anderson JL, et al. Vancomycin pharmacokinetics, renal handling, and nonrenal clearances in normal human subjects. Clin Pharmacol Ther (1988) 43(5):565-70. doi:10.1038/ clpt.1988.74

49. Zar FA, Bakkanagari SR, Moorthi KM, Davis MB. A comparison of vancomycin and metronidazole for the treatment of Clostridium difficile-associated diarrhea, stratified by disease severity. Clin Infect Dis (2007) 45(3):302-7. doi:10.1086/519265

50. Hermsen ED, Hanson M, Sankaranarayanan J, Stoner JA, Florescu MC, Rupp ME. Clinical outcomes and nephrotoxicity associated with vancomycin trough concentrations during treatment of deep-seated infections. Expert Opin Drug Saf (2010) 9(1):9-14. doi:10.1517/14740330903413514

51. Polk RE, Healy DP, Schwartz LB, Rock DT, Garson ML, Roller K. Vancomycin and the red-man syndrome: pharmacodynamics of histamine release. $J$ Infect Dis (1988) 157(3):502-7. doi:10.1093/infdis/157.3.502

52. Wong JT, Ripple RE, MacLean JA, Marks DR, Bloch KJ. Vancomycin hypersensitivity: synergism with narcotics and "desensitization" by a rapid continuous intravenous protocol. J Allergy Clin Immunol (1994) 94(2 Pt 1):189-94. doi:10.1053/ai.1994.v94.a55251
53. Renz CL, Thurn JD, Finn HA, Lynch JP, Moss J. Antihistamine prophylaxis permits rapid vancomycin infusion. Crit Care Med (1999) 27(9):1732-7. doi:10.1097/00003246-199909000-00006

54. Black E, Lau TT, Ensom MH. Vancomycin-induced neutropenia: is it doseor duration-related? Ann Pharmacother (2011) 45(5):629-38. doi:10.1345/aph. 1P583

55. Von Drygalski A, Curtis BR, Bougie DW, McFarland JG, Ahl S, Limbu I, et al. Vancomycin-induced immune thrombocytopenia. N Engl J Med (2007) 356(9):904-10. doi:10.1056/NEJMoa065066

56. Christie DJ, van Buren N, Lennon SS, Putnam JL. Vancomycin-dependent antibodies associated with thrombocytopenia and refractoriness to platelet transfusion in patients with leukemia. Blood (1990) 75(2):518-23.

57. Yazganoglu KD, Ozkaya E, Ergin-Ozcan P, Cakar N. Vancomycin-induced drug hypersensitivity syndrome. J Eur Acad Dermatol Venereol (2005) 19(5):648-50. doi:10.1111/j.1468-3083.2005.01228.x

58. Hassaballa H, Mallick N, Orlowski J. Vancomycin anaphylaxis in a patient with vancomycin-induced red man syndrome. Am J Ther (2000) 7(5):319-20. doi:10.1097/00045391-200007050-00010

59. Hsiao SH, Chou CH, Lin WL, Lee EJ, Liao LH, Chang HJ, et al. High risk of cross-reactivity between vancomycin and sequential teicoplanin therapy. J Clin Pharm Ther (2012) 37(3):296-300. doi:10.1111/j.1365-2710.2011.01291.x

60. Ben m'rad M, Leclerc-Mercier S, Blanche P, Franck N, Rozenberg F, Fulla Y, et al. Drug-induced hypersensitivity syndrome: clinical and biologic disease patterns in 24 patients. Medicine (Baltimore) (2009) 88(3):131-40. doi:10.1097/ MD.0b013e3181a4d1al

61. Vauthey L, Uçkay I, Abrassart S, Bernard L, Assal M, Ferry T, et al. Vancomycin-induced DRESS syndrome in a female patient. Pharmacology (2008) 82(2):138-41. doi:10.1159/000142729

62. Young S, Ojaimi S, Dunckley H, Douglas MW, Kok J, Fulcher DA, et al. Vancomycin-associated drug reaction with eosinophilia and systemic symptoms syndrome. Intern Med J (2014) 44(7):694-6. doi:10.1111/imj.12462

63. Bernstein EF, Schuster M. Linear IgA bullous dermatosis associated with vancomycin. Ann Intern Med (1998) 129(6):508-9. doi:10.7326/0003-4819-129-6199809150-00022

64. Nousari HC, Kimyai-Asadi A, Caeiro JP, Anhalt GJ. Clinical, demographic, and immunohistologic features of vancomycin-induced linear IgA bullous disease of the skin. Report of 2 cases and review of the literature. Medicine (Baltimore) (1999) 78(1):1-8. doi:10.1097/00005792-199901000-00001

65. Klein PA, Callen JP. Drug-induced linear IgA bullous dermatosis after vancomycin discontinuance in a patient with renal insufficiency. J Am Acad Dermatol (2000) 42(2 Pt 2):316-23. doi:10.1016/S0190-9622(00)90102-6

66. Marik PE, Ferris N. Delayed hypersensitivity reaction to vancomycin. Pharmacotherapy (1997) 17(6):1341-4.

67. Smith PF, Taylor CT. Vancomycin-induced neutropenia associated with fever: similarities between two immune-mediated drug reactions. Pharmacotherapy (1999) 19(2):240-4. doi:10.1592/phco.19.3.240.30912

68. Wazny LD, Daghigh B. Desensitization protocols for vancomycin hypersensitivity. Ann Pharmacother (2001) 35(11):1458-64. doi:10.1345/aph.1A002

69. Lin RY. Desensitization in the management of vancomycin hypersensitivity. Arch Intern Med (1990) 150(10):2197-8. doi:10.1001/archinte.1990.00390210145031

70. Corey GR, Kabler H, Mehra P, Gupta S, Overcash JS, Porwal A, et al. Single-dose oritavancin in the treatment of acute bacterial skin infections. $N$ Engl J Med (2014) 370(23):2180-90. doi:10.1056/NEJMoa1310422

71. Corey GR, Kollef MH, Shorr AF, Rubinstein E, Stryjewski ME, Hopkins A, et al. Telavancin for hospital-acquired pneumonia: clinical response and 28-day survival. Antimicrob Agents Chemother (2014) 58(4):2030-7. doi:10.1128/AAC. 02330- 13

72. Stryjewski ME, Barriere SL, O’Riordan W, Dunbar LM, Hopkins A, Genter FC et al. Efficacy of telavancin in patients with specific types of complicated skin and skin structure infections. J Antimicrob Chemother (2012) 67(6):1496-502. doi:10.1093/jac/dks081

73. Stryjewski ME, Chu VH, Cabell CH, Fowler VG. Issues in the management of endocarditis caused by resistant gram-positive organisms. Curr Infect Dis Rep (2004) 6(4):283-91. doi:10.1007/s11908-004-0049-7

74. Stryjewski ME, Lentnek A, O’Riordan W, Pullman J, Tambyah PA, Miró JM, et al. A randomized Phase 2 trial of telavancin versus standard therapy in patients with uncomplicated Staphylococcus aureus bacteremia: the assure study. BMC Infect Dis (2014) 14:289. doi:10.1186/1471-2334-14-289 
75. Rubinstein E, Corey GR, Stryjewski ME, Kanafani ZA. Telavancin for the treatment of serious gram-positive infections, including hospital acquired pneumonia. Expert Opin Pharmacother (2011) 12(17):2737-50. doi:10.1517/ 14656566.2011.633511

76. Chavanet P. The ZEPHyR study: a randomized comparison of linezolid and vancomycin for MRSA pneumonia. Med Mal Infect (2013) 43(11-12):451-5. doi:10.1016/j.medmal.2013.09.011

Conflict of Interest Statement: The authors declare that the research was conducted in the absence of any commercial or financial relationships that could be construed as a potential conflict of interest.
Received: 04 December 2013; accepted: 16 October 2014; published online: 31 October 2014.

Citation: Rubinstein E and Keynan Y (2014) Vancomycin revisited - 60 years later. Front. Public Health 2:217. doi: 10.3389/fpubh.2014.00217

This article was submitted to Infectious Diseases, a section of the journal Frontiers in Public Health.

Copyright (C) 2014 Rubinstein and Keynan. This is an open-access article distributed under the terms of the Creative Commons Attribution License (CC BY). The use, distribution or reproduction in other forums is permitted, provided the original author(s) or licensor are credited and that the original publication in this journal is cited, in accordance with accepted academic practice. No use, distribution or reproduction is permitted which does not comply with these terms. 